
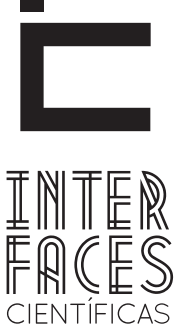

DIREITO

\title{
A POSSIBILIDADE E A EXTENSÃO DOS LIMITES AOS DIREITOS FUNDAMENTAIS
}

\author{
Evinis da Silveira Talon ${ }^{1}$
}

\section{RESUMO}

Os direitos fundamentais são o centro do Constitucionalismo Contemporâneo e da perspectiva de proteção das pessoas, fundamentando e legitimando o Estado Democrático de Direito, principalmente por ocuparem atualmente papel de destaque na Constituição. Contudo, a preocupação do Estado com a proteção dos direitos fundamentais e da dignidade da pessoa humana permeia a zona cinzenta entre a proteção deficiente e a excessiva proteção, que não deixa de ser deficiente, pois os direitos fundamentais são tensionais, apresentando colisões internas e externas, o que torna claro que, havendo proteção excessiva de um direito fundamental, outro direito fundamental será significativamente relativizado ou suprimido, seja por aspectos normativos, seja por insuficiência orçamen- tária ou banalização. Dessa forma, assim como os direitos fundamentais estão sujeitos a limites, esses limites, também, são restringidos, especialmente pela vedação ao retrocesso, impedindo que conquistas históricas sejam suprimidas arbitrariamente, e pelo conceito de mínimo existencial. Assim, atualmente, mais importante do que a definição de novos direitos e a ampliação horizontal dos direitos fundamentais é a análise dos limites verticais ou qualitativos, ou seja, a abordagem de cada direito e de suas limitações.

\section{PALAVRAS-CHAVE}

Direitos Fundamentais. Limites. Mínimo Existencial. Retrocesso. 


\section{ABSTRACT}

Fundamental rights are at the center of Contemporary Constitutionalism and people protection perspective, grounding and legitimizing the democratic rule of law, especially by currently occupy a prominent role in the Constitution. However, the State's concern with the protection of fundamental rights and human dignity permeates the gray area between poor protection and over-protection, it is still deficient, as fundamental rights are $\mathrm{BP}$, with internal and external collisions , which makes clear that, with excessive protection of a fundamental right, another fundamental right will be significantly relativized or suppressed, either by regulatory, or by insufficient budget or trivialization.

\section{RESUMEN}

Los derechos fundamentales están en el centro del Constitucionalismo Contemporáneo y de la perspectiva de protección de las personas, fundamentando y legitimando el Estado Democrático de Derecho, principalmente porque en la actualidad ocupan una función destacada en la Constitución. No obstante, la preocupación del Estado en la protección de los derechos fundamentales y la dignidad humana penetra la zona gris entre la mala protección y la protección excesiva, que es todavía deficiente, porque los derechos fundamentales son conflictivos, mostrando colisiones internas y externas, que deja claro que, con excesiva protección de un derecho fundamental, otro derecho fundamental se relativiza de forma significativa o es eliminado, sea por as-
Thus, as well as fundamental rights are subject to limits, these limits are also restricted, especially for sealing the reverse, preventing historical achievements are removed arbitrarily, and the concept of existential minimum. So now, more important than the definition of new rights and the horizontal expansion of fundamental rights is the analysis of vertical or qualitative limits, ie the approach of each law and its limitations.

\section{KEYWORDS}

Fundamental Rights. Limits. Existential Minimum. Rewind. pectos normativos, sea por presupuesto insuficiente o banalización. Por lo tanto, así como los derechos fundamentales están sujetos a límites, estos límites también se restringen, especialmente por la prohibición de retroceso, impidiendo que logros históricos se eliminan arbitrariamente, y lo concepto de mínimo existencial. Así, actualmente, más importante que la definición de nuevos derechos y la expansión horizontal de los derechos fundamentales es el análisis de límites verticales o cualitativos, es decir, el enfoque de cada derecho y sus limitaciones.

\section{PALABRAS-CLAVE}

Derechos Fundamentales. Límites. Mínimo. Retroceso. 


\section{INTRODUÇ̄̃O}

Os direitos fundamentais qualificam o Estado em que estão inseridos, definindo se o referido Estado possui características mais liberais ou sociais. Ademais, a definição da legitimidade estatal permeia a análise do maior ou menor grau de respeito aos direitos fundamentais. Nesse ponto, a Constituição Federal de 1988 é pioneira no Brasil na priorização e na extensão dos direitos fundamentais.

Contudo, o caráter analítico e extenso do rol constitucional de direitos enseja problemas como a multiplicação dos conflitos e das demandas judiciais, aumentando significativamente a juridificação e a judicialização das relações sociais, o que impõe um debate sobre o alcance de cada direito, seja na sua abordagem individual, seja na análise da colidência com outros direitos fundamentais.

Nesse diapasão, abordar-se-á, inicialmente, a diferença conceitual entre direitos humanos e direitos fundamentais, expondo, da mesma forma, as principais correntes fundamentadoras desses direitos. A partir desses delineamentos, analisar-se-á o caráter limitado dos direitos fundamentais na Constituição Federal brasileira, destacando o aspecto relativo e a possibilidade de limitações. Por fim, serão perquiridos os limites dos limites aos direitos fundamentais, assim como a vedação ao retrocesso social, teorias que impedem a supressão absoluta ou significativa dos direitos fundamentais.

O desiderato da presente pesquisa, portanto, é destacar até qual ponto são legítimos e necessários os limites aos direitos fundamentais, diante da tensão entre uma proteção deficiente e uma proteção excessiva e que, por consequência, tornaria conflituosas as relações entre os direitos fundamentais.

Justifica-se a presente pesquisa, porque é imprescindível definir a linha que separa as limitações legítimas ou necessárias e as limitações arbitrárias e violadoras do mínimo existencial, conteúdo intangível dos direitos fundamentais.

0 método de abordagem é hipotético-dedutivo, uma vez que se indaga, por meio da razão e da formulação de hipótese, sobre a legitimidade e a extensão das limitações de direitos fundamentais na contemporaneidade, além do seu caráter de imprescindibilidade. 0 método de procedimento é monográfico e a pesquisa, essencialmente bibliográfica, é aplicada, com o desiderato de se obter aportes teóricos para aplicação prática. A abordagem do problema será por uma pesquisa qualitativa, afastando-se, por incompatibilidade, de uma abordagem quantitativa ou estatística, que não supriria adequadamente as necessidades do presente estudo.

\section{DIREITOS HUMANOS E DIREITOS FUNDAMENTAIS: DISTINÇÕES E FUNDAMENTO}

Atualmente, os direitos fundamentais "são o parâmetro de aferição do grau de democracia de uma sociedade. E a sociedade democrática, ao mesmo tempo, apresenta-se como condição para a eficácia dos direitos fundamentais" (CORDEIRO, 2012, p. 28). É inegável que os direitos fundamentais representam o núcleo de uma Constituição que pretenda ter como desiderato assegurar a dignidade da pessoa humana.

Contudo, uma das grandes celeumas jurídicas contemporâneas no âmbito constitucional é a conceituação dos direitos fundamentais, o que torna imprescindível a conceituação, consequentemente, de termos igualmente poliédricos, como direitos humanos, direitos do homem e direitos naturais.

Para esse escopo, o magistério de Canotilho (1998, p. 259) é de suma relevância:

As expressões direitos do homem e direitos fundamentais são frequentemente utilizadas como sinônimas. Segundo a sua origem e significado poderíamos 
distingui-las da seguinte maneira: direitos do homem são direitos válidos para todos os povos e em todos os tempos; direitos fundamentais são os direitos do homem, jurídico-institucionalmente garantidos e limitados espacio-temporalmente. Os direitos do homem arrancariam da própria natureza humana e daí o seu caráter inviolável, intertemporal e universal; os direitos fundamentais seriam os direitos objetivamente vigentes numa ordem jurídica concreta.

Há, ainda, autores que entendem os direitos humanos como aqueles consagrados no plano internacional, ao contrário dos direitos fundamentais, que ocupam o ápice do ordenamento jurídico interno de cada país, especificamente no âmbito constitucional.

Nessa esteira, Leite (2014, p. 33) salienta que os direitos humanos, em decorrência da universalidade, "estão reconhecidos tanto na Declaração Universal de 1948 quanto nos costumes, princípios jurídicos e tratados internacionais. Já os direitos fundamentais estão positivados nos ordenamentos internos de cada Estado, especialmente nas suas Constituições".

Ademais, importante destacar que nem todo direito fundamental é considerado um direito humano, da mesma forma que nem todo direito humano é um direito fundamental. Um dos principais exemplos seria o direito à vida, previsto no artigo $5^{\circ}$, caput, da Constituição Federal de 1988 como um direito fundamental no Brasil. Por outro lado, em alguns ordenamentos jurídicos existe a pena de morte, razão pela qual em alguns países o direito à vida pode não ser fundamental, em que pese seja reconhecido como um direito humano no âmbito internacional (LEITE, 2014).

Se a definição desses direitos é tarefa hercúlea, a busca da fundamentação é tarefa de igual dificuldade, sobretudo pela forte divergência entre universalismo e relativismo dos direitos humanos.

Assim, entre as posições que tentam explicar a fundamentação dos direitos humanos e que contribuem significativamente para a análise dos direitos fundamentais, o jusnaturalismo apresenta-se como a tese que considera a existência de direitos anteriores ao Estado, ainda que não positivados. Nesse esteio, tais direitos encontrar-se-iam já no estado de natureza.

Assim, nas palavras de Nader (2012, p. 191), "os jusnaturalistas apresentam uma concepção dualista, convictos de que, paralelamente à ordem institucionalizada pelo Estado, haveria o Direito Natural, ordem não escrita, não promulgada pelos homens". Por essa perspectiva, o direito natural seria um paradigma para o legislador, decorrendo da natureza humana, sua fonte.

Aliás, tal concepção dualista já encontrava amparo desde Aristóteles, para quem, conquanto houvesse distinção entre direito natural e direito positivo, não havia superioridade de um sobre o outro. Como ressalta Bobbio (2006), Aristóteles diferenciava o direito natural do direito positivo ao considerar que aquele tem em toda parte a mesma eficácia e prescreve ações cuja bondade é objetiva (ações que são boas em si mesmas), enquanto o direito positivo teria eficácia somente nas comunidades políticas singulares em que é posto e deve ser cumprido da forma prescrita pela lei.

Por oportuno, o direito natural caracteriza-se pela imutabilidade, sendo critérios valorativos de justiça e inerentes a toda sociedade, o que, portanto, melhor se amolda à concepção de justiça.

Por outro lado, o positivismo apresenta-se de forma oposta ao jusnaturalismo. Em outras palavras,

O positivismo jurídico é uma concepção do direito que
nasce quando 'direito positivo' e 'direito natural' não
mais são considerados direito no mesmo sentido, mas
o direito positivo passa a ser considerado como direito
em sentido próprio. (BOBBIO, 2006, p. 26).

Assim, o positivismo jurídico importa-se com a validade em detrimento da justiça e da eficácia.

No positivismo, a lei é um comando do soberano. Em outras palavras, 
[...] ela é identificada como jurídica pela sua origem, e não pelo conteúdo. Ou seja, ela pode ser 'justa' ou 'injusta' sem que isso afete a sua qualificação jurídica. 0 jus deixa de identificar-se com o justum, e passa a ser identificado com o jussum (comando) do soberano. (BARZOTTO, 2007, p. 14).

Uma crítica que se faz ao positivismo jurídico é que não considera especificamente o conteúdo da lei, desconsiderando a ideia de justiça, tão relevante para o jusnaturalismo, significando o império da lei.

Destarte, observa-se que os direitos humanos são de difícil fundamentação, havendo divergência se são preexistentes ao direito posto como decorrentes da ideia de justo e injusto e apenas reconhecidos pelo ordenamento jurídico ou se são efetivamente criados pelo direito posto e encontram nele a sua fundamentação. Assim, no presente estudo, buscar-se-á uma análise neopositivista, com a conciliação entre as ideias jusnaturalistas e juspositivistas.

Pelo exposto, um fundamento absoluto dos direitos fundamentais é dificilmente alcançado. Trata-se de expressão de difícil conceituação, seja pela sua ausência de conteúdo ou porque, quando este aparece, possui termos avaliativos emanados pelo intérprete. Da mesma forma, em razão da mutabilidade histórica dos direitos fundamentais, são direitos relativos e sem possibilidade de atribuição de um fundamento absoluto. Além disso, há enorme heterogeneidade desses direitos, muitas vezes conflitantes entre si. Por fim, alguns desses direitos representam liberdades, enquanto outros resultam em poderes, havendo uma inegável conflituosidade interna (BOBBIO, 1992).

0 reconhecimento paulatino dos direitos fundamentais, também, é um fator que demonstra a enorme heterogeneidade entre tais direitos, reconhecidos em momentos históricos totalmente distintos e por razões diversas.

Com efeito, a teoria geracional foi criada pelo jurista francês de origem checa, Karel Vasak, em Confe- rência no Instituto Internacional de Direitos Humanos de Estrasburgo, em 1979. Naquele momento, Vasak relatou a maior intensificação de determinados conjuntos de direitos em certos momentos históricos.

Os direitos fundamentais caracterizam-se pela historicidade, porquanto o seu "surgimento" ocorre em determinadas épocas, segundo leciona a doutrina. Entretanto, na realidade, tais direitos não surgem nessas épocas, mas sim são juridicamente reconhecidos, pois a necessidade social de proteção preexiste à positivação desses direitos, isto é, há um caráter declaratório, e não constitutivo.

Assim, os direitos fundamentais são frutos de intensas reivindicações e acontecimentos históricos impactantes, razão pela qual, como se verá, a limitação desses direitos jamais poderá ser arbitrária ou irracional, mas apenas exercida como instrumento imprescindível para a conservação e a ampliação desses mesmos direitos.

\section{LIMITAÇÕES E O CARÁTER NÃO ABSOLUTO DOS DIREITOS FUNDAMENTAIS}

Contemporaneamente, os direitos fundamentais são analisados por uma leitura relativista. Noutros termos, os direitos fundamentais não são absolutos na ordem jurídica - apesar de sua fundamentalidade -, mas sim compreendidos e analisados caso a caso de modo relativo ou limitado (FERNANDES, 2010).

Os direitos fundamentais possuem um âmbito de proteção, assim compreendido como campo de incidência normativa ou suporte fático, o qual, ao menos em princípio, se sujeita a intervenções (SARLET, 2013). A proteção deve ser efetiva, mas não ilimitada, pois, se assim o fosse, haveria incompatibilidade lógica para a coexistência de todos os direitos fundamentais reconhecidos.

O âmbito de proteção de um direito fundamental abrange os diferentes pressupostos fáticos instituídos 
pela respectiva norma jurídica. Trata-se, com outras palavras, do bem jurídico protegido, ou seja, do objeto tutelado, que nem sempre se afigura de fácil identificação, especialmente em decorrência das indeterminações semânticas invariavelmente presentes nos textos que contemplam direitos fundamentais. Por outro lado, considerando que nenhuma ordem jurídica pode proteger os direitos fundamentais de maneira ilimitada, a ideia de que os direitos fundamentais não sejam absolutos não tem oferecido maiores dificuldades e tem sido amplamente aceita no direito constitucional contemporâneo. (SARLET, 2013, p. 198).

Assim, é comum a afirmação de que inexiste hierarquia entre direitos fundamentais, não havendo superioridade entre os mesmos, apesar da circunstancial posição topográfica que ocupam na Constituição. Somente no caso concreto é que se pode verificar a extensão e os limites a serem impostos a um direito fundamental (FERNANDES, 2010).

Conforme Cordeiro (2012) é a inevitabilidade dos momentos de tensão ou antagonismo entre bens protegidos pela Constituição, aliada à necessidade de coexistência desses inúmeros direitos, que permite a conclusão de que não existem direitos fundamentais absolutos. Portanto, os direitos fundamentais são, por natureza, imanentemente dotados de uma reserva geral de ponderação. Aliás, o caráter sistemático da Constituição, também, impõe que haja uma convivência harmônica entre os direitos fundamentais. Dessa forma, não há hierarquia axiológica entre as normas constitucionais.

Portanto, uma vez demonstrado que os direitos fundamentais não são absolutos ou ilimitados, é inegável que são passíveis de limitações.

Segundo Sarlet (2013, p. 200):

Limites aos direitos fundamentais, em termos sumários, podem ser definidos como ações ou omissões dos poderes públicos (Legislativo, Executivo e Judiciário) ou de particulares que dificultem, reduzam ou eliminem o acesso ao bem jurídico protegido, afetando o seu exercício (aspecto subjetivo) e/ou diminuindo de- veres estatais de garantia e promoção (aspecto objetivo) que resultem dos direitos fundamentais.

As restrições aos direitos fundamentais possuem três funções: a) função adequadora, pela qual a restrição de um desses direitos possibilita que outros sejam exercidos sem sobreposições, com a maior eficácia possível; b) função dirimente, especificamente relacionada ao contexto da colisão de direitos fundamentais, caracterizando-se pelo exercício conflitante por parte de dois ou mais titulares de direitos contrapostos, razão pela qual a restrição a alguns deles serve para evitar a repetição desses conflitos futuramente, tornando prescindíveis ulteriores intervenções administrativas ou jurisdicionais; c) função comunitária, ligada à necessidade de conjugar os direitos fundamentais e os bens ou interesses coletivos que mereçam tutela, de maneira que a restrição funcione como garantia desses bens ou interesses comunitários que demandam preservação (GOUVEIA, 2005).

Divergência doutrinária, contudo, existe sobre a localização dessas limitações. Em outras palavras, enquanto alguns autores entendem que as limitações são externas e que os direitos nascem absolutos, outros defendem que tais limitações integram o próprio direito fundamental em si.

Analisando essas diferentes propostas, Alexy (2011, p. 277) afirma:

0 conceito de restrição a um direito sugere a existência de duas coisas - o direito e sua restrição -, entre as quais há uma relação de tipo especial, a saber, uma relação de restrição. Se a relação entre direito e restrição for definida dessa forma, então, há, em primeiro lugar, o direito em si, não restringido, e, em segundo lugar, aquilo que resta do direito após a ocorrência de uma restrição, o direito restringido. Essa é a concepção que, normalmente de forma crítica, é denominada de teoria externa. Embora a teoria externa possa admitir que, em um ordenamento jurídico, os direitos apresentam-se sobretudo ou exclusivamente como direitos restringidos, ela tem que insistir que eles são também concebíveis sem restrições. Por isso, segundo a teoria externa, entre o conceito de direito e o conceito de restrição não existe 
nenhuma relação necessária. Essa relação é criada somente a partir da exigência, externa ao direito em si, de conciliar os direitos de diversos indivíduos, bem como direitos individuais e interesses coletivos.

Portanto, essa teoria externa distingue os direitos fundamentais e suas restrições eventualmente impostas. Assim, haveria um direito ilimitado que, por meio da imposição de eventuais restrições, converter-se-ia em direito limitado. Com isso, existiriam duas posições referentes aos direitos, sendo uma posição prima facie, correspondente ao direito antes de sua limitação, e uma posição definitiva, que equivale ao direito já limitado (SARLET, 2013).

A teoria interna, por sua vez, não diferencia o direito e sua restrição. Para ela, haveria apenas o direito com um determinado conteúdo. 0 termo restrição é substituído pelo conceito de limite. Nesse diapasão, reconhece-se que as

[...] dúvidas acerca dos limites do direito não são dúvidas sobre quão extensa pode ser sua restrição, mas dúvidas sobre seu conteúdo. Quando eventualmente se fala em "restrições" no lugar de "limites", então, se fala em “restrições imanentes”. (ALEXY, 2011, p. 277-278).

Portanto, a teoria interna transmite a ideia de que um direito fundamental sempre existirá com seu conteúdo determinado, nascendo já com seus limites, que são fronteiras implícitas, de natureza apriorística, que não se confundem com as restrições. Para a teoria interna, o direito tem o seu alcance definido anteriormente, de modo que sua restrição se revela desnecessária e até mesmo impossível logicamente (SARLET, 2013).

\section{A IMPRESCINDÍVEL PROTEÇÃO EFICIENTE: OS LIMITES DOS LIMITES E A VEDAÇÃO AO RETROCESSO SOCIAL}

Quando se busca uma proteção eficiente dos direitos fundamentais, deve-se imaginar a exata linha entre o estritamente imprescindível e a banalização protetiva. Proteção deficiente e excessiva proteção resultam, em última análise, na fragilização dos direitos fundamentais.

A banalização dos direitos fundamentais debilita a sua própria fundamentalidade, uma vez que restringe a operatividade daqueles direitos que são realmente fundamentais e, da mesma forma, amplia a esfera daqueles que carecem desta fundamentalidade, prejudicando com isso a hierarquia de valores que deve ser concedida aos direitos fundamentais (GOUVEIA, 2005).

Dessa forma, "a identificação dos limites dos direitos fundamentais constitui condição para que se possa controlar o seu desenvolvimento normativo, partilhado com o legislador ordinário" (SARLET, 2013, p. 200).

Como exposto anteriormente, "o problema parece não estar no conceito de restrição a um direito fundamental, mas exclusivamente na definição dos possíveis conteúdo e extensão dessas restrições" (ALEXY, 2011, p. 276). Ora, admitindo-se que os direitos fundamentais são realmente limitados ou limitáveis, interessa definir até que ponto tais limitações são legítimas.

De forma elucidativa, Alexy (2011, p. 295-296) afirma:

Da natureza principiológica das normas de direitos fundamentais decorriam não apenas a restrição e a restringibilidade dos direitos fundamentais em face de princípios colidentes, mas também que sua restrição e sua restringibilidade têm limites. Uma restrição a um direito fundamental somente é admissível se, no caso concreto, aos princípios colidentes for atribuído um peso maior que aquele atribuído ao princípio de direito fundamental em questão. Por isso, é possível afirmar que os direitos fundamentais, enquanto tais, são restrições à sua própria restrição e restringibilidade.

Uma das propostas que busca definir um ponto máximo de aceitação dos limites é a tese dos limites dos limites, surgida no âmbito constitucional como instrumento de defesa dos direitos fundamentais contra atos abusivos emanados do Poder Legislati- 
vo ou do Executivo, reconhecendo-se que, em que pese os direitos fundamentais não sejam absolutos, somente o texto constitucional poderia limitá-los (FERNANDES, 2010).

Não se deve esquecer que qualquer limitação aos direitos fundamentais deve ser pautada pelo respeito ao núcleo essencial ou intangível desses direitos, decorrência lógica, principalmente, do supraprincípio constitucional da dignidade da pessoa humana.

Se o homem não é um instrumento de projetos alheios, mas derradeiramente um fim em si mesmo, os direitos fundamentais devem direcionar-se ao pleno desenvolvimento da dignidade da pessoa humana, o que somente será possível se respeitados direitos fundamentais mínimos e conteúdos mínimos dos direitos fundamentais. Trata-se daquilo que a doutrina, no viés dos direitos fundamentais sociais, denomina de mínimo existencial.

Assim, o mínimo existencial é a dimensão essencial e inalienável dos direitos da pessoa, incluindo, especialmente, os direitos fundamentais que demandam prestações estatais. Ademais, quanto aos níveis primários e essenciais, requisitos para o exercício da liberdade e da garantia de igualdade de oportunidades, direitos como a saúde, a assistência social, a educação, o acesso à justiça e a moradia demonstram-se como direitos fundamentais de liberdade e viabilizadores da igualdade de chances (SILVA, 2005). 0 mínimo existencial significa, em última análise, unidade de direitos.

Ao mesmo tempo, a dicotomia rígida entre direitos negativos e positivos vem sendo paulatinamente superada. No lugar de uma compreensão fragmentada, passa-se a trabalhar com um conceito unitário de direitos fundamentais, sem ignorar suas diferenças, buscando-se uma teoria que atribua efetividade concreta aos direitos fundamentais sociais independentemente da atuação do legislador (intermediação legislativa infraconstitucional) ou do administrador (condução de políticas públicas). Nesse desiderato, encontra-se no mínimo existencial uma saída. (CORDEIRO, 2012, p. 26-27)
O conceito de mínimo existencial torna-se mais relevante quando se considera que, atualmente, os direitos fundamentais encontram forte proteção constitucional, seja pelo extenso rol de direitos fundamentais, seja pelo detalhamento constitucional na análise de vários desses direitos. Portanto, o mínimo existencial atua como uma garantia em face da banalização desses direitos, da mesma forma que possibilita um parâmetro do que não seria restringível.

Outra importante perspectiva limitadora das restrições aos direitos fundamentais é a tese da vedação ao retrocesso social, que proíbe a desconsideração de direitos consagrados e sobre os quais já se estabeleceu consenso sobre a proteção normativa.

Para Leite (2014), a vedação ao retrocesso social é um princípio geral de direito constitucional e de direito fundamental. No Brasil, encontraria previsão constitucional expressa baseada no direito à segurança no artigo $5^{\circ}$, caput, e no artigo $6^{\circ}$. Ainda segundo o autor, no primeiro dispositivo constitucional citado seria um direito de primeira dimensão (de liberdade), enquanto no artigo $6^{\circ}$ seria um direito de segunda dimensão (igualdade).

A proibição do retrocesso relaciona-se com propostas jusnaturalistas e juspositivistas, por se dirigir à preservação da segurança jurídica. A relação entre vedação ao retrocesso e segurança jurídica é muito bem destacada por Sarlet (2011, p. 434):

\footnotetext{
[] proibição do retrocesso guarda íntima relação com a noção de segurança jurídica. Assim, convém relembrar que, havendo (ou não) menção expressa no âmbito do direito positivo a um direito à segurança jurídica, de há muito, pelo menos no âmbito do pensamento constitucional contemporâneo, se enraizou a ideia de que um autêntico Estado de Direito é sempre também - pelo menos em princípio e num certo sentido - Estado de segurança jurídica, já que, do contrário, também o 'governo das leis' (até pelo fato de serem expressão da vontade política de um grupo) poderá resultar em despotismo e toda a sorte de iniquidades.
} 
Quando se pensa em vedação ao retrocesso, deve-se considerar o conjunto de lutas, batalhas e guerras que, historicamente, reivindicaram os atuais direitos humanos e fundamentais. Segundo Gorczevski (2009), a conquista dos direitos humanos é recheada de violência e consiste em processo ainda em desenvolvimento, pois tais direitos não são estáticos.

O Supremo Tribunal Federal tem utilizado frequentemente a tese da vedação ao retrocesso social, afirmando, ainda, que deve ser preservado o mínimo existencial e que as restrições aos direitos fundamentais também são limitadas.

Como exemplo, é possível citar a decisão do Supremo Tribunal Federal que determinou o custeio, pelo Estado, de serviços hospitalares prestados por instituições privadas em prol de pacientes do Sistema Único de Saúde (SUS), atendidos pelo Serviço de Atendimento Móvel de Urgência (SAMU) nos casos de urgência e de inexistências de leitos na rede pública.

Argumentou-se, no caso em comento, que o Estado tem o dever de prestar assistência à saúde e proteger a vida, não podendo alegar a reserva do possível, que comprometeria o núcleo básico que qualifica o mínimo existencial. Por fim, salientou-se que seria justificável a interferência judicial, diante da necessidade de observância de certos parâmetros constitucionais, como a proibição de retrocesso social, proteção ao mínimo existencial, vedação da proteção insuficiente e proibição de excesso (BRASIL, Supremo Tribunal Federal, Segunda Turma, ARE 727864 AgR, Relator: Min. Celso de Mello, 2014).

No controle das restrições aos direitos fundamentais - assim como para o controle de constitucionalidade -, o método adequado é o da proporcionalidade, precipuamente por meio da cláusula de proibição de proteção deficiente (CORDEIRO, 2012).

Ademais, a proporcionalidade deve ser aplicada não apenas para a restrição a um direito fundamental por si só, mas também na ponderação entre direitos fundamentais, ou seja, quando um direito fundamental, colidindo com outro, deve ser restringido, em determinado caso concreto, de acordo com os critérios de necessidade, adequação e proporcionalidade em sentido estrito.

\begin{abstract}
[] afiguram-se possíveis limitações decorrentes da colisão de um direito fundamental com outros direitos fundamentais ou bens jurídico-constitucionais, o que legitima o estabelecimento de restrições, ainda que não expressamente autorizadas pela Constituição. Em outras palavras, direitos fundamentais formalmente ilimitados (isto é, desprovidos de reserva) podem ser restringidos caso isso se revelar imprescindível para a garantia de outros direitos constitucionais, de tal sorte que há mesmo quem tenha chegado a sustentar a existência de uma verdadeira 'reserva geral imanente de ponderação'. Tais hipóteses exigem, no entanto, cautela redobrada por parte dos poderes públicos. (SARLET, 2013, p. 201).
\end{abstract}

Por derradeiro, as restrições aos direitos fundamentais devem sempre ser racionais, o que demanda as características da generalidade e da abstratividade, abarcando, por conseguinte, uma multiplicidade de indivíduos. Com isso, proíbe-se que a legislação crie limitações casuísticas a direitos fundamentais, que seriam verdadeiras discriminações arbitrárias (FERNANDES, 2010)

Os direitos fundamentais são o núcleo da Constituição Federal e do Estado Democrático de Direito, merecendo especial proteção, mormente quando se considera o mínimo necessário desses direitos, que não pode ser abalado por qualquer tipo de restrição, eis que lastreado no princípio da dignidade da pessoa humana. Esse mínimo encontra amparo na própria natureza do ser enquanto fim em si mesmo, e não instrumento de projetos de terceiros.

De forma clara, Carvalho (2010, p. 742) destaca:

A aposição de limites e restrições aos direitos fundamentais não deve, no entanto, esvaziar o direito fundamental na sua totalidade, isto é, na globalidade do seu sentido ou significado real: há um núcleo duro ou 
essencial, que deve ser protegido, e que se traduz em fundamento, nos elementos que constituem a própria substância do direito fundamental, e que são dele inseparáveis, e não meramente acidentais.

Assim, é cediço que os direitos fundamentais, por serem limitados, encontram restrições que, em última instância, concedem-lhes o caráter da fundamentalidade, afastando-os das banalizações de uma proteção excessiva.

Nesse diapasão, as restrições racionais que respeitem o mínimo existencial, a vedação ao retrocesso e o núcleo intangível desses direitos, desde que se estabeleçam de maneira proporcional, são legítimas e imprescindíveis para a própria coexistência do extenso rol de direitos fundamentais instituídos na Constituição Federal de 1988.

\section{CONCLUSÃO}

Apesar das divergências conceituais, é quase uníssona a afirmação de que os direitos fundamentais não são absolutos ou ilimitados. Dessa forma, o ponto central de qualquer análise sobre os direitos fundamentais deve ser definir o limite dessas restrições.

Nesse ponto, como demonstrado, há uma linha tênue entre a proteção deficiente e a excessiva proteção, sendo que esta, apesar de não ser aparente, também, fragiliza os direitos fundamentais, por significar a banalização desses direitos e permitir um direcionamento equivocado da proteção a direitos desprovidos da própria fundamentalidade. Dessa forma, as restrições aos direitos fundamentais são imprescindíveis para que continuem tendo essa posição de destaque no âmbito constitucional.

Contudo, a escolha pela restrição dos direitos fundamentais deve ser igualmente limitada, sob pena de se atingir o núcleo intangível desses direitos, ou seja, a esfera não suprimível, que nos direitos fundamentais sociais é conhecida como mínimo existencial.
Da mesma forma, a restrição não pode ser casuística ou irracional, tampouco desconsiderar as intensas lutas pela concretização dos atuais direitos fundamentais, sob pena de resultar em um inadmissível retrocesso social.

Conclui-se, portanto, que as restrições aos direitos fundamentais, que não são ilimitados ou absolutos, é legítima e imprescindível, para que continuem ocupando o zênite da Constituição e sejam, verdadeiramente, dotados de fundamentalidade, desde que tais restrições sejam, também, limitadas ou racionalmente adequadas e respeitem o conteúdo mínimo dos direitos fundamentais.

\section{REFERÊNCIAS}

\author{
ALEXY, Robert. Teoria dos direitos fundamentais. São \\ Paulo: Malheiros, 2011.
}

BARZOTTO, Luis Fernando. 0 positivismo jurídico contemporâneo: uma introdução a Kelsen, Ross e Hart. 2.ed. Porto Alegre: Livraria do Advogado, 2007.

BOBBIO, Norberto. A era dos direitos. Rio de Janeiro: Campus, 1992.

BOBBIO, Norberto. 0 positivismo jurídico: estudos de filosofia do direito. Trad. Márcio Pugliesi, Edson Bini, Carlos E. Rodrigues. São Paulo: Ícone, 2006.

BRASIL. Supremo Tribunal Federal, Segunda Turma. Agravo Regimental no Recurso Extraordinário com Agravo 727864/PR. Relator: Min. Celso de Mello. Brasília, 4 nov. 2014. Disponível em: <http://www.stf.jus. br/portal/jurisprudencia/ listarJurisprudencia.asp?s $1=\% 28727864 \% 2 E N U M E \% 2 E+O U+727864 \% 2 E A C$ M\%2E\%29\&base =baseAcordaos\&url=http://tinyurl. com/pbetc9m>. Acesso em: 15 nov. 2014.

CANOTILHO, José Joaquim Gomes. Direito Constitucional e Teoria da Constituição. 3.ed. Coimbra: Almedina, 1998. 
CARVALHO, Kildare Gonçalves. Direito Constitucional. 16.ed. Belo Horizonte: Del Rey, 2010.

CORDEIRO, Karine da Silva. Direitos fundamentais sociais: dignidade da pessoa humana e mínimo existencial, o papel do poder judiciário. Porto Alegre: Livraria do Advogado, 2012.

FERNANDES, Bernardo Gonçalves. Curso de Direito Constitucional. 2.ed. Rio de Janeiro: Lumen Juris, 2010.

GORCZEVSKI, Clovis. Direitos humanos, educação e cidadania: conhecer, educar, praticar. Santa Cruz do Sul: EDUNISC, 2009.

GORCZEVSKI, Clovis. Direitos Humanos: dos primórdios da humanidade ao Brasil de hoje. Porto Alegre: Imprensa Livre, 2005.

GOUVEIA, Jorge Bacelar. Manual de direito constitucional. v.2. Coimbra: Almedina, 2005.
LEITE, Carlos Henrique Bezerra. Manual de direitos humanos. 3.ed. São Paulo: Atlas, 2014.

NADER, Paulo. Filosofia do Direito. 21.ed. Rio de Janeiro: Forense, 2012.

SARLET, Ingo Wolfgang. Notas introdutórias ao sistema constitucional de direitos e deveres fundamentais. In: CANOTILHO, J. J. Gomes; MENDES, Gilmar F.; STRECK, Lenio L.; SARLET, Ingo Wolfgang (Coords.). Comentários à Constituição do Brasil. São Paulo: Saraiva/Almedina, 2013. p.183-212.

SARLET, Ingo Wolfgang. A eficácia dos direitos fundamentais: uma teoria geral dos direitos fundamentais na perspectiva constitucional. 10.ed. Porto Alegre: Livraria do Advogado, 2011.

SARLET, Ingo Wolfgang. Dignidade da pessoa humana e direitos fundamentais na Constituição Federal de 1988. 8.ed. Porto Alegre: Livraria do Advogado, 2010. SILVA, Anabelle Macedo. Concretizando a Constituição. Rio de Janeiro: Lumen Juris, 2005.

1. Advogado Professor de Direito Penal da Faculdade Dom Alberto (Santa Cruz do Sul-RS), mestrando em Direito pela Universidade de Santa Cruz do Sul (UNISC-RS), especialista em Direito Constitucional, Direito Penal e Processual Penal, Filosofia e Sociologia pela Universidade Gama Filho (UGF-RJ), pós-graduando em Direito Público pela Pontifícia Universidade Católica de Minas Gerais (PUC-MG). E-mail: evinistalon@hotmail.com 